\title{
LOS ESTADOS FINANCIEROS $Y$ EL VALOR DE LA EMPRESA
}

\author{
Hans Frank \\ Profesor Principal de ESAN
}

C omo parte de nuestras actividades empresariales, financieras, económicas o académicas, a menudo recibimoso encontramos en revistas especializadas o periódicos, memorias de empresas, estados financieros de los últimos periodos, balances, estados de resultados y hasta indicadores financieros de empresas agrupadas por sectores económicos.

La Conasev publica anualmente, de acuerdo con la Clasificación Internacional Industrial Uniforme (CIU), Estados financieros empresariales c Indicadores financieros empresariales, documentos consultados por muchos analistas y consultores como elementos referenciales paracomparar la situación de las empresas que están evaluando.

Al revisar e interpretar estos estados financieros cabe hacerse las siguientes preguntas:

¿Presentan estos estados realmente la situación cconómica financiera de la empresa?

Si se vende la empresa, ¿se podrá obtener el equivalente a lo que se presenta como su valor patrimonial?, ¿tal vez más?

Al liquidar la empresa, ¿quedará para sus accionistas el valor que figura como su patrimonio o capital accionario?

Para el caso de las empresas cuyas acciones se cotizan en bolsa, ¿coincide el valor contable de las acciones con el valor bursátil o valor de mercado?

Me adelanto a responder que en la gran mayoría de casos la respuesta a estas preguntas va a ser un contundente ¡NO! En este artículo, que no tiene el carácter rigurosode una investigación científica, se pretende demostrar las razones de esta negación.

Planteando un cjemplo simple, quiero 
adelantarles que al 30 de setiembre de 1995, la empresa Telefónica del Perú S.A. presentaba acciones comunes clase $\mathrm{B}$ a un valor nominal de $\mathrm{S} / 1,00$, mientras que de sus estados financieros surgían acciones a un valor contable de $S / .1,55 \mathrm{y}$, finalmente, en el mercado la acción se cotizaba a S/. 4,71 .

Es muy posible que este artículo pueda incomodar a algunos colegas contadores públicos y también a auditores, pero si bien es cierto que en algún caso puntual puede haber alguna responsabilidad de su parte, el fondo de la respuesta está en que el valor contable no es igual al valor económico, ni al valor de mercado, ni al valor de liquidación ni al valor de la empresa en marcha.

En la contabilización de las diversas transacciones que ocurren en las empresas. los contadores aplican diferentes criterios. En una oportunidad, un profesor universitario, al dar inicio a su curso de formulación de estados financieros dijo: "Si encargamos a cinco contadores preparar los estados financieros de una empresa, pidiéndoles que trabajen aisladamente sin consultar entre ellos, es muy seguro que obtengamos cinco balances y estados de resultados diferentes". Esto to he podido comprobar hace algunas semanas cuando encargué a los participantes de un programa de especialización, la resolución de un caso cuyo objetivo era formular los estados financieros para una empresa partiendo de sólo 16 transacciones comerciales. Al revisar los trabajos desarrollados, pude comprobar que los diez grupos aplicaron criterios diferentes, por lo cual llegaron finalmente a diez balances y estados de resultados también diferentes.

Es conveniente señalar, además, que los estados financieros normalmente están debidamente auditados y refrendados por una firma auditora. Sin embargo, debemos considerar que los dictámenes incluyen un párrafo que dice: "En nuestra opinión, los estados financieros que se acompañan presentan razonablemente, en todos sus aspectos significativos, la situación financiera de ...", y, por otra parte, que es práctica común que los auditores, antes de iniciar su examen de auditoría, soliciten a la empresa la firma de la "carta de gerencia", por la cual la empresa asume la responsabilidad de toda la información proporcionada a los auditores, lo que en parte exime a éstos de responsabilidades resultantes de su informe sobre la real situación financiera de la empresa auditada.

\section{Presentación de los estados financieros ajustados por la inflación}

Afortunadamente, desde cl año 1991 estamos recibiendo estados financieros ajustados por la inflación, lo que nos debe dar una mayor seguridad y confianza respecto a las cifras planteadas y a su posibilidad de comparación a través del tiempo.

Hoy también resulta más aceptable -o más bien necesario- que la empresa presente su balance y resultados desde el punto de vista tributario y con un enfoque más bien económico financiero. En el extremo nos encontramos con empresas que hacen una presentación extracontable basada en el valor contable patrimonial ajustado (relativo a valor, no a inflación), que trata de valorizar el patrimonio como una forma de llegar con mayor aproximación al valor de las acciones, dentro de los límites contables y económicos.

El Decreto Legislativo 627, del Ajuste Integral por Inflación, independientemen- 
te de la aplicación de los índices correctores aplicados en función del tiempo transcurrido, establece límites de expresión en concordancia con el concepto conservador de los principios contables. Estos límites, que siempre significan ajustes hacia abajo, provocan, por lo general, la subvaluación de los bienes que posee una empresa.

Ejemplos de estos límites son los siguientes:

\section{Existencias : Valor de mercado Valor de reposición \\ Inversiones : Valor de participación patrimonial Valor bursátil \\ Activo Fijo : Valor de tasación \\ Valor de utilización económica \\ Valor de recuperación futura \\ Valor de reposición}

Como adelantamos, la aplicación de esta norma conduce a considerar valores declinantes, lo que hace que los estados financieros resultantes no sean una base adecuada para fines de valuación.

\section{Valorización basada en el valor contable patrimonial ajustado}

En la aplicación de este método, se parte de los estados financieros a una fecha dada y se revisa cuidadosamente las cifras, de la misma forma como proceden los auditores, pero aplicando criterios de valuación, los que no neccsariamente causan ajustes hacia ahajo, sino que también pueden, en algunos casos, significar ajustes hacia arriba.
Las cuentas que deben revisarse con mayor atención y de las que surgen mayormente las necesidades de ajustes por diferencias al aplicar los criterios de valuación se describen a continuación.

\section{Valores negociables e inversiones}

De acucrdo con los principios contables, los valores negociables se presentan al costo ajustado (por la inflación) o al valor de mercado, el que fuere más bajo.

Puede ocurrir que en ciertos casos nos abstengamos de aplicar este principio, basados en que la declinación del valor de determinadas acciones es temporal y que a corto plazo se producirá una recuperación.

En forma opuesta, pero desde el enfoque de valorización de la empresa, puede ocurrir que el valor de cotización de determinadas acciones se eleve y que en aplicación de este enfoque se decida considerar el mayor valor para acercarnos a una más justa valuación.

\section{Cuentas por cobrar}

El punto clave de la valorización de esta cuenta es la necesidad de crear provisiones por morosidad o por incobrabilidad. En la práctica se aplican muy diversos criterios que nos pueden llevar a sobrevaluar o subvaluar esta cuenta.

Para el caso del sistema financiero, la Superintendencia de Banca y Seguros ha dado normas muy estrictas que conducen a considerar carteras pesadas muy importantes, que con una buena gestión de recuperación pueden reducirse en forma muy significativa. 


\section{Existencias}

De acuerdo con los principios de contabilidad, las existencias -ya sea mercaderías, productos terminados, materias primas o repuestos-aparecen en el balance al costo ajustado o al valor de mercado, el que fuere más bajo.

La verificación física de las existencias puede determinar la necesidad de crear una provisión por desmedro o pérdida de valor debido al deterioro u obsolescencia, como también por faltantes.

Desde el punto de vista del valor es posible encontrar casos en que el valor del mercado se ha incrementado en forma permanente y las existencias tienen efectivamente un valor superior.

Con el objeto de cuantificar la diferencia entre el valor al costo y el valor de mercado -superior-, vamos a plantear una situación referida a una empresa productora de harina de pescado que al 31 de diciembre mantiene un stock de 10 mil toneladas de harina.

Para esta empresa, el costo ajustado de sus existencias de harina de pescado es de 220 dólares la tonelada, o sea un total de 2.200 .000 dólares, pero el valor de mercado, y con tendencia a subir, es de 530 dólares la tonelada, con un total de 5.300 .000 dólares, lo que significa una diferencia de 3.100 .000 dólares. Esta diferencia, desde el punto de vista económico financiero, puede considerarse como una utilidad bruta potencial.

Establecidos los gastos de venta y el impuesto a la renta es posible determinar el mayor valor que se puede añadir a la empresa.

\section{Activo fijo}

La proyección de una vida útil inadecuada y la no consideración de valores residuales nos conduce en la práctica a que los valores de los activos fijos que aparecen en los balances no sean realistas. Laobsolescencia tecnológica podría ser otro factor de distorsión. En estos casos, dependiendo de si se trata de un inmueble, un vehículo o un computador, para establecer el valor real del activo fijo podemos ayudarnos con el valor de tasación, el valor de utilización económica, el valor de recuperación futura y también con el valor de reposición.

\section{Valores intangibles}

Una empresa nueva puede haber contabilizado algunos valores intangibles, como los costos de constitución, los costos de puesta en marcha o los costos de mercadotecnia (introducción de un nuevo producto). En estos casos habrá que evaluar la capacidad de la empresa para absorber estos costos en un determinado periodo de tiempo.

Una empresa en marcha puede haber generado otros intangibles, como costos de experimentación, patentes, marcas o franquicias. Igualmente, en estos casos habrá que realizar un análisis económico para determinar la capacidad para amortizar estos costos, y en el caso de la marea, para evaluar su valor real de mercado.

Por otra parte, en las transferencias de empresas se presenta la necesidad de valorizar intangibles como parte de la compraventa. En este último caso, el valor surgirá como parte de la negociación entre compradores y vendedores. Podemos recordar que en el caso de la compra del 62 por ciento de las acciones de la Compañía Nacional 
de Cerveza S.A., la Cervecería Backus y Johnston S.A. pagó 30 millones de dólares por la marca Pilsen y su correspondiente mercado.

\section{Pasivos}

Se entiende que los auditores deben de haber cumplido con una adecuada verificación de todos los pasivos que forman parte de las diferentes cuentas. Sin embargo, pueden surgir algunas discrepancias con relación a las contingencias que puede tener una determinada empresa.

A modo de ejemplo podemos plantear los casos de juicios en proceso, acotaciones tributarias y periodos pasados pendientes de fiscalización. En estas situaciones, ninguna estimación resulta aceptable en los casos de venta de empresas. Lo que suelc hacerse es que la empresa vendedora deje una garantía en calidad de fideicomiso en una entidad financiera, para que ésta pueda ser aplicada si se efectivizan los pasivos contingentes materia de los hechos pendientes de definición.

Los ajustes que se decida aplicar, ya sea hacia arriba o hacia abajo, nos conducirán necesariamente a un nuevo valor patrimonial ajustado, el que servirá de base para calcular el valor ajustado de las acciones, esta vez no aplicando conceptos contàblesconservadores, sinocriterioseconómicos de valor real.

\section{Valor de la empresa en marcha}

Cuando se trata de valorizar las acciones de una empresa en marcha debemos considerar que, además de los activos efectivamente contabilizados, pueden haber surgi- do ciertos valores intangibles, tales como: mercado, marca, ubicación del negocio, know-how, capacidad gerencial y sistemas operativos. Este mayor valor se denomina good-will y puede definirse comoel mayor valor que puede tener una empresa en marcha debido a los elementos antes mencionados.

Es necesario señalar que así como puede haber un good-will, también puede haber casos de empresas que, por el contrario, tengan un bad-will, loque de hecho nos conduce a un menor valor, porque han perdido mercado, sus productos han declinado, su maquinaria es tecnológicamente obsoleta, no hay capacidad gerencial, etc.

El planteamiento de valor de empresa en marcha puede ser aplicado a la venta de los grifos de Petroperú, operación realizada hace ya más de dos años. Hubo varias estaciones de servicio que se vendieron a más del doble de su valor de tasación, como las ubicadas en las avenidas Coronel Portillo y Salaverry -cruce con Prescott-, pero hubo un grifo ubicado en la Panamericana Sur, en el pueblo de Chilca, que no se vendio, pues su volumen de ventas, infraestructura $\mathrm{e}$ imagen no justificaban el valor de tasación asignado.

\section{Valor de la empresa basado en el potencial de ganancias}

Éste es un método cuya aplicación está muy difundida en la valorización de empresas en marcha. Se le conoce tambien como valor de rendimiento y es el más aceptado desde el punto de vista económico financiero. Consiste en determinar el valor actual del flujo de caja proyectado. La proyección suele hacerse para diez años y considerando al final un valor residual 
que también se descuenta, incorporándolo al flujo.

Este método es totalmente diferente en el sentido que no toma en cuenta para nada el balance general de la empresa, sino los resultados proyectados de las operaciones, partiendo del flujo de ingresos y egresos netos de efectivo que se generan en los años futuros.

Es muy seguro que las proyecciones cambien si se toma en cuenta el punto de vista del vendedor o del comprador, especialmente en aspectos relacionados con los volúmenes y precios de venta futuros, así como con el comportamiento de los costos y gastos.

El otro punto clave es la tasa de descuento que se aplicará, y que tomará en cuenta los riesgos que se asume. Es común para el comprador usar tasas de entre $25 \mathrm{y}$ 20 por ciento, con lo que se proyecta recuperar la inversion en 465 afios, mientras el vendedor suele usar tasas de entre 15 y 10 por ciento, con lo cual se obtiene valores actuales bastante diferentes para iniciar la negociación.

Vale la pena recordar, aunque hoy resulte algo histórico, que en el año 1973 , cuando el Gobierno de ese entonces trató de negociar la compra de las empresas del Grupo Grace (Sociedad Paramonga Ltda, Cartavio S. A. y otras), el precio ofertado fue de 500 millones de dólares y la demanda de los representantes del Grupo Grace fue de 1.800 millones de dólares. Nunca se llegó a un acuerdo y las empresas fueron finalmente expropiadas.

Otro caso reciente en que los compradores aplicaron el concepto del potencial de ganancias es el de la compra de acciones de la Compañía Peruana de Teléfonos S.A. y de Entel Perú S.A. por parte de la Empresa Telefónica de España. El monto pagado -2.002 millones de dólares-estuvo basado en esta metodología.

Finalmente, cabe señalar que las metodologías de valuación de empresas plantean formas mixtas en las que se considera tanto el valor contable patrimonial con valores ajustados como el valor actual del flujo de caja proyectado, considerando un determinado peso para cada uno de estos valores.

\section{Conclusión}

Como conclusión de este artículo es posible afirmar que los estados financieros que recibimos al final de cada año cumplen normalmente con requerimientos contables, legales y tributarios, pero no pueden tomarse como una buena base para llegar a determinar el valor de una empresa en marcha. 